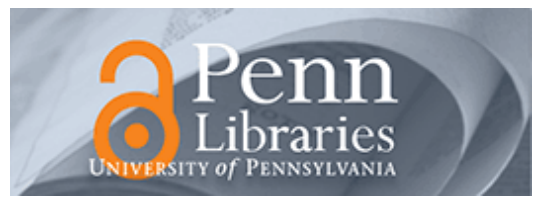

University of Pennsylvania

ScholarlyCommons

Management Papers

Wharton Faculty Research

$2-2006$

\title{
Venture Capitalists and Cooperative Start-up Commercialization Strategy
}

David H. Hsu

University of Pennsylvania

Follow this and additional works at: https://repository.upenn.edu/mgmt_papers

Part of the Business Administration, Management, and Operations Commons, and the Entrepreneurial and Small Business Operations Commons

Recommended Citation

Hsu, D. H. (2006). Venture Capitalists and Cooperative Start-up Commercialization Strategy. Management Science, 52 (2), 204-219. http://dx.doi.org/10.1287/mnsc.1050.0480

This paper is posted at ScholarlyCommons. https://repository.upenn.edu/mgmt_papers/110

For more information, please contact repository@pobox.upenn.edu. 


\title{
Venture Capitalists and Cooperative Start-up Commercialization Strategy
}

\author{
Abstract \\ This paper examines the possible impact of venture capital (VC) backing on the commercialization \\ direction of technology-based start-ups by asking: To what extent (if at all) do VC-funded start-ups \\ engage in cooperative commercialization strategies (strategic alliances or technology licensing, or both) \\ relative to a comparable set of start-ups, and with what consequences? To address these questions, I \\ assemble a novel data set that matches firms receiving a federal research and development subsidy \\ through the U.S. Small Business Innovative Research program to VC-funded firms by observable \\ characteristics in five technology-intensive industries. These data allow decoupling of cooperative activity \\ resulting from start-up development via the passage of calendar time from that due to association with \\ VCs. An analysis of the 696 start-ups in the sample (split by an external funding source) suggests \\ substantial boosts in both cooperative activity associated with VC-backed firms and in the likelihood of an \\ initial public offering.
}

\section{Keywords}

entrepreneurial ventures, venture capital, cooperation, commercialization strategy, strategic alliances, initial public offerings

\section{Disciplines}

Business Administration, Management, and Operations | Entrepreneurial and Small Business Operations 


\title{
VENTURE CAPITALISTS AND COOPERATIVE START-UP COMMERCIALIZATION STRATEGY
}

\author{
DAVID H. HSU \\ The Wharton School, University of Pennsylvania \\ 2000 Steinberg Hall - Dietrich Hall, Philadelphia, PA 19104
}

\section{INTRODUCTION}

This paper examines the possible impact of venture capital (VC) backing on the commercialization direction of technology-based start-ups by asking: to what extent (if at all) do VC-backed start-ups engage in cooperative commercialization strategies (strategic alliances and/or technology licensing) relative to a comparable set of start-ups, and with what consequences? To address these questions, I assemble a novel dataset that matches firms receiving a federal research and development subsidy through the Small Business Innovative Research program to VC-backed firms by observable characteristics in five technology-intensive industries. This method helps decouple cooperative activity resulting from start-up development associated with the passage of calendar time from that due to association with VCs. An analysis of the 701 start-ups in the sample (split by external funding source) suggests substantial boosts in cooperative activity associated with VC-backed firms, as well as a number of start-up performance implications.

By now the strategic and organizational benefits of inter-firm collaboration - extending reach to complementary assets, conserving resources, obtaining new competencies/learninghave been well-documented across a number of locations and industries (e.g., Gulati, 1998; Stuart, 2000). These benefits are balanced against expected costs arising from transaction, governance, or other organizational costs (e.g., managerial complacency) when organizations consider the decision to self-commercialize or seek collaborative commercialization, leading to observed variation in commercialization strategy (Eisenhardt and Schoonhoven, 1996).

Cooperative commercialization strategies may be particularly important for start-ups since entrepreneurial ability to expand the boundaries of their firm through backward or forward integration may be limited due to binding resources constraints. For start-ups, the hurdles to inter-firm collaboration may be accentuated for four reasons: (1) start-ups face high search costs in locating appropriate cooperation partners, (2) start-ups may not want to engage in cooperative activity because they fear expropriation, (3) start-ups are of unknown quality, and so would-be cooperative partners have difficulty evaluating them, and (4) start-ups are not sufficiently developed to engage in cooperative relationships. Each of these potential obstacles is discussed, together with how VCs may mitigate these them in enabling cooperative start-up strategies.

A first impediment to start-up cooperative behavior is simply that they face higher search costs for potential cooperation partner matching. This can result from start-ups' reluctance in broadcasting their product or service development, especially in settings in which ventures are privately-held and entrepreneurs fear alerting potential competitors of their strategic direction. While researchers have highlighted the role of prior alliance networks as a source of information about firms' existence, capabilities, and needs that can lead firms to enter new alliances (e.g., Kogut, Shan, and Walker, 1994), de-novo start-ups may not have access to this channel relative to more established firms. VC information intermediation may help start-ups get matched with cooperation partners due to their intensive due diligence and monitoring processes, together with their knowledge of the needs and capabilities of other firms. 
A second obstacle to start-up cooperation may be entrepreneurial fear of expropriation when negotiating with potential cooperation partners. Start-up idea disclosure is a necessary part of cooperation contracting, and the threat of entrepreneurial idea expropriation can affect both ex-ante start-up innovation incentives and start-up commercialization strategy (Gans, Hsu and Stern, 2002). Start-up involvement in a VC portfolio can mitigate appropriation concerns by increasing the cost to cooperation partner defection. By broadening the network in which the start-up is engaged (to incorporate the VC's network of contacts), defecting cooperation partners will face a larger potential penalty, since perverse behavior will be broadcast faster and more pervasively through the network (Coleman, 1988; Robinson and Stuart, 2003).

A third potential obstacle to start-up collaborative commercialization is that start-ups may be of unknown quality to potential cooperation partners. The literature in this area observes that endorsements or certifications of reputable parties can signal to relatively uninformed outsiders the quality of the unknown start-up (Megginson and Weiss, 1991; Stuart, Hoang and Hybels, 1999). Endorsements from known affiliates (such as VCs) may be particularly important for start-ups without established reputations or for start-ups with particularly uncertain technology.

A final potential stumbling block to start-up cooperation may be that these firms are not yet sufficiently developed to be attractive to potential cooperation partners. Recent literature on the business development role of VCs has emphasized, for example, their ability to professionalize employment practices (Hellmann and Puri, 2002) at start-ups. Taken as a whole, the foregoing discussion on how VCs may help facilitate start-up cooperation suggests a first set of empirical predictions in this study:

- Hypothesis 1: VC funding is associated with boosts in start-up cooperative behavior.

- Hypothesis 2: VCs differ in reputation, and start-ups affiliated with higher reputation VCs forge more cooperative outcomes.

The prior literature also suggests a number of predictions regarding organizational performance following cooperative behavior and as a result of $\mathrm{VC}$ funding. A first group of studies examined the association between network ties and innovative output (patents). In the setting of biotechnology start-ups, Shan, Walker and Kogut (1994) find that cooperative behavior is linked with innovative output. Similarly, Ahuja (2000) that direct and indirect ties in the chemicals industry is linked with patent output.

A number of studies have also examined the link between network ties and initial public offerings. Stuart, Hoang and Hybels (1999) find the hazard of IPO increases with the reputation of entrepreneurial ventures' strategic alliance and investment bank affiliates. Stuart (2000) links IPO performance to characteristics of the cooperation partner, finding that alliances with larger firms confer more value (better performance) to the entrepreneurial venture. Taken together, the foregoing discussion suggests a second set of empirical predictions:

- Hypothesis 3: VC funding is positively associated with the likelihood of a start-up firm IPO.

- Hypothesis 4: VCs differ in reputation, and start-ups backed by more reputable VCs have an enhanced probability of achieving an IPO.

- Hypothesis 5: Of the start-ups that go public, those that have VC backing have a more reputable IPO underwriter. 
The empirical strategy is depicted schematically in Figure 1. The distance $y$ is the postfunding level of cooperation, the distance $x$ is the pre-funding level of cooperation. Testing the first two hypotheses involves estimating $y=\mathrm{f}(V C, x, z)$, where $V C$ is an indicator variable for VC-backed start-ups, and $z$ is a set of control variables. Since $y$ is a non-negative count variable, I use negative binomial regressions for estimating these equations.

Figure 1 about here

Testing the performance hypotheses involve estimating both the likelihood that a firm undergoes an IPO and the level of IPO underwriter reputation, using in both cases the same set of right hand side variables as before. Probit and Cox hazard models are used to estimate the IPO equations, and OLS regressions are used to estimate the IPO underwriter reputation models. Before describing the data set and variables, it will be useful to examine some institutional details of the two external financing mechanisms, SBIR and VC, used in the study to understand the comparability of matched start-ups based on different external funding sources.

The SBIR program is administered through the U.S. Small Business Administration (SBA), and American-owned, independent firms with 500 or fewer employees are eligible. Award winners are selected based on "small business qualification, degree of innovation, technical merit, and future market potential" (SBA web site). Proposals are peer-reviewed for technical and commercial merit, and funds are awarded competitively. Unlike VC financing, the government through the SBIR program does not take an equity stake in exchange for the grant. Moreover, the program is the largest of its kind, having awarded \$1.5B in 2001, up from its first year of operation in 1983, during which it awarded \$45M (SBA website).

SBIR funding takes place in two stages, with phase I earmarked for proof of concept and idea development and phase II awards reserved for technology development and exploring commercial potential. Phase I awards were capped at $\$ 100,000$ during the sample period (ending in 1999), while phase II awards during the sample period were capped at $\$ 750,000$. Only those firms with a phase I award are considered for a phase II award. For the period 1991-93, for all 11 participating federal agencies, the average ratio of funded phase I proposals to proposals received was $13.3 \%$ (USGAO, 1995). The competitiveness for phase II awards was much more intense, at about 5\%. For more details of the SBIR program, see Lerner (1999).

VCs select the firms they wish to fund by reviewing business plans, which consider both the technical and commercial merits of an idea. VCs tend to concentrate their investments in a much narrower range of technical projects - particularly in the communications, information technology, and biotechnology sectors - relative to the SBIR program. To address this issue, sampled SBIR projects are restricted to encompass only those in which VCs concentrate their investments (in five high technology sectors).

Despite these differences in selecting projects between the two financing mechanisms, there are many similarities in the inputs to- and characteristics of- the SBIR and VC financed projects. First, both forms of funding are highly selective. Second, the levels of funding for successful VC and SBIR recipients have not been that different historically (Lerner, 1999), though this has clearly changed since the mid-1990s. Because successful SBIR recipients typically receive multiple phase II awards for technology development, the average project may have received comparable levels of outside funding. Third, the age of organizations at the time that they received external financing (VC or SBIR) is comparable (Lerner, 1999). In sum, while 
SBIR and VC represent different funding sources, controlled comparisons of projects funded by each will help us isolate the effect of $\mathrm{VC}$ association on start-up commercialization strategy.

A list of phase II SBIR funded firms from 1988 through 1999 was generously provided to me by the SBA. Restricting the sample to phase II SBIR recipients was meant to establish some uniformity in the overall sample regarding promising technologies (relative to venture-backed ones). This list of SBIR awardees was further restricted to those operating in one of five SIC industries: biotechnology (SIC 2836), industrial machinery \& equipment (SIC 35), electronic \& electrical equipment (SIC 36), scientific instruments (SIC 38), and pre-packaged computer software (SIC 7372). From this list of phase II awardees, I sampled every fifth SBIR-backed company. This effort led to identification of 661 SBIR-backed firms. I then tried to identify a venture-backed match for each of the firms by using the following hierarchical procedure: the SIC industry had to match, the year of funding had to match, the year of founding had to match, and the geographic location (at the state level) had to match. If no match was found using all four criteria, the geographic location constraint was dropped. If no match was found using the remaining three criteria, the year of founding criteria was dropped, etc., though the SIC industry match was always retained (no match was declared if the SIC industry criterion was not satisfied). I eliminated those venture-backed start-ups that had received SBIR funding. This process yielded identification of 454 VC-backed firms.

To find cooperation data, I relied on the SDC Platinum Alliances database to obtain strategic alliance and licensing data. I gathered counts of cooperation events using the year in which the firm received external funding (SBIR or VC) as the dividing line between pre- and post-cooperation events. Unfortunately, 53.6\% of the SBIR-backed firms were not included in the SDC database, as compared to $13.2 \%$ of the VC-backed firms. Since these measures of postfunding cooperation are the dependent variables in the analyses, this reduced the usable number of observations to a total of $701 .^{1}$

Additional databases are used to compile further information about these firms: Venture Economics is consulted for financing amounts and experience of VCs; SDC Platinum's Public Offerings database provides IPO data; Corptech Directory provides industry, location, sales and employee information (including historic information); and the U.S. Patent and Trademark Office provides patent data. ${ }^{2}$ The following paragraphs describe the data used in the empirical analyses.

The dependent variables in the analyses are measures of cooperation and start-up performance. Cooperation is measured through count variables. Post-funding $R \& D$ alliances is the number of R\&D alliances following the introduction of external funding (mean $=1.6$ for the overall sample). There are significant differences between VC and SBIR sub-sample postfunding $R \& D$ alliances (mean $=1.95$ vs. 0.63 , respectively) in this univariate comparison. A similar variable measures alliance and technology license counts. A second set of dependent variables examines performance consequences. IPO is a dummy variable $=1$ if an initial public offering was achieved as of January 2002 (VC and SBIR means $=0.44$ and 0.18 , respectively). $I B$ reputation is a measure of investment bank underwriter reputation taken from Carter, Dark and Singh (1998). The variable ranges from a low of zero to a high of nine, and is based on underwriter placement in tombstone announcements. The IB reputation means for the $\mathrm{VC}$ and SBIR sub-samples are $=7.08$ and 4.01 , respectively.

The independent variables in the analyses span a range of start-up characteristics. The key independent variable is ever $V C$-backed. This measure takes the value of 1 if the start-up received venture capital funding as of January 2002, and the data are from the Venture 
Economics database. Nearly three quarters of the entire sample received VC funding, with about $40 \%$ of the SBIR sub-sample receiving subsequent VC funding. As a measure of VC reputation, high VC IPO record is a dummy $=1$ if the VC's prior IPO record up to the time of funding the target start-up placed it in the upper half of the sample (the threshold value is 21 IPOs, and mean $=0.47$ ). This variable, of course, can only be constructed for the sub-sample that was VC funded. A second set of independent variables control for pre-funding cooperative activity, either in prefunding $R \& D$ alliances $($ mean $=0.93$ ) or in aggregate alliance and licensing pre-funding cooperative events (mean $=1.98)$. A third set of control variables are defined for start-up year

founded (mean = June 1981), year funded (mean = June 1993), the net present value of aggregate external monetary inflows as of 1999, as well as pre-funding levels of sales, employees, and patents. A final set of control variables capture location and industry effects: dummy variables are defined for Massachusetts-located (mean $=0.16)$ and California-located $($ mean $=0.32)$. The industry controls include biotechnology ( $15 \%$ of the sample), software ( $25 \%$ of the sample), electronic equipment (24\%), industrial equipment (12\%), and scientific/medical equipment $(24 \%)$.

\section{EMPIRICAL RESULTS AND DISCUSSION}

In R\&D alliance negative binomial regressions, where the dependent variable is a count of start-up post-funding $R \& D$ alliances, the estimated $\mathrm{VC}$ funding coefficient is positive and significant at the $1-5 \%$ levels, depending on the specification. These results control for a number of start-up characteristics: pre-funding $R \& D$ alliances, year founded, year funded, total dollar inflows, high employees, high sales, pre-funding patents, Massachusetts located start-up, California located start-up, and a set of industry controls for biotechnology, software, electrical equipment, and scientific instruments (industrial equipment is the excluded category). The estimated ever received $V C$ funding coefficient in the fully specified model is economically significant, with an implied 1.68 incidence ratio.

Neither varying the definition of VC funding to demarcate initial external funding source, nor dropping the observations that correspond to start-ups that received VC funding after receiving SBIR funding initially, qualitatively alter the results. ${ }^{3}$ The sample was also restricted as a robustness check to start-ups founded before the early- to mid-1990s, when VC funding skyrocketed, to establish further comparability between the sub-samples. This did not change the results. Varying the definition of cooperation to number of post-funding sales and marketing alliances or the number of technology licenses does not substantively change the results. Furthermore, the results hold when zero-inflated negative binomial regressions are employed.

A second set of empirical results confirm the IPO predictions. In probits of the likelihood of achieved IPO by January 2002 using the same set of regressors as before, the ever received $V C$ funding estimate is positive and statistically significant at the $1 \%$ level. The estimated coefficients imply that a discrete change from being not $\mathrm{VC}$-backed to ever having received $\mathrm{VC}$ funding is associated with a $19-25 \%$ boost in the likelihood of an IPO, depending on the specification. The same results are achieved using a Cox hazard regression on yearly data to more precisely capture the timing of events and to more properly deal with the right censoring of the data. In these analyses, the clock starts when the start-up is founded, and failure occurs when the start-up undergoes an IPO.

To explore the differential effect of more reputable VCs, I examine the sub-sample of firms that received $\mathrm{VC}$-backing, and look for heterogeneous start-up value associated with more 
reputable VCs. The variable of interest is high VC IPO record. Estimated implied incidence rate ratios on high VC IPO record are 1.71 and 1.60, respectively, and the estimates are statistically significant at the 5\% level. VC reputation also appears to matter in the case of IPOs for the current start-up venture. A probit of IPO as of January 2002 using the fully specified model suggests that having a high reputation $\mathrm{VC}$ is associated with a $15 \%$ boost in the likelihood of an IPO (evaluated at the mean of the other independent variables), a result that is significant at the $1 \%$ level. This result holds in a hazard model using a similar specification.

Finally, OLS regressions of investment banker reputation for the sample of start-ups that realized an IPO indicate that ever received VC funding is positive and significantly related to investment bank reputation at the $1 \%$ level. The measure of investment banker reputation is the 0-9 scale developed by Carter, Dark and Singh (1998).

In conclusion, this paper examined the possible impact of venture capital (VC) backing on the commercialization direction of technology-based start-ups by asking: to what extent (if at all) do VC-backed start-ups engage in cooperative commercialization strategies (strategic alliances and/or technology licensing), and with what consequences? An analysis of the resulting 701 start-ups (split by external funding source) suggests substantial boosts in VC-backed cooperative activity, as well as several start-up performance implications.

\section{References Available from the Author}

Figure 1. Empirical Strategy Conceptualization

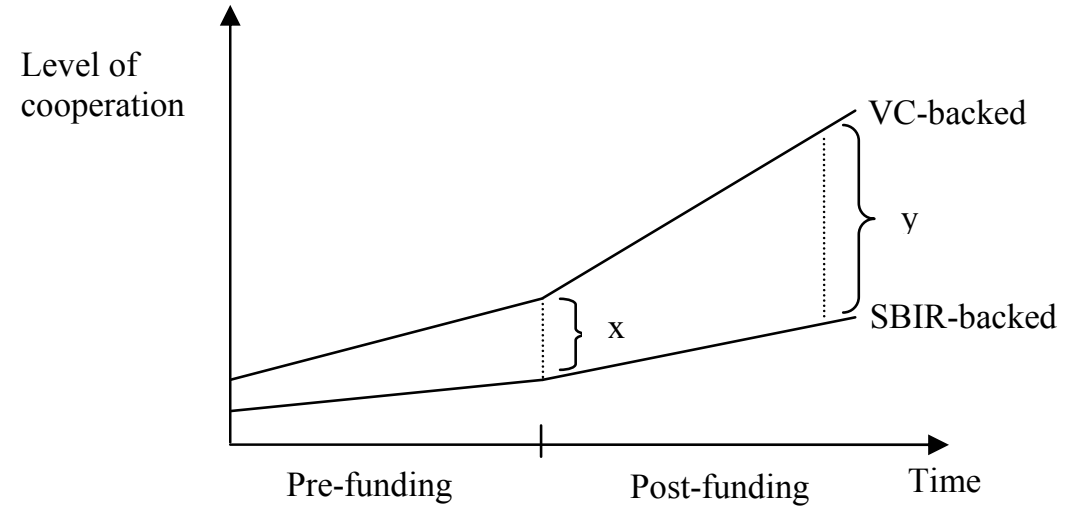

\footnotetext{
${ }^{1}$ Perhaps it is not surprising that SDC would carry much better coverage for VC-backed firms, since these firms are more visible. The disparity in the coverage, however, does raise questions of comparability of the sub-samples in the study, especially relative to the original matching procedure. Collecting and controlling for other firm-level variables, however, should mitigate concerns about other factors that might affect observed variation in cooperation. ${ }^{2}$ To address the issue of bias as a result of missing observations of the dependent variable previously discussed, I performed $t$-tests of equal means of key independent variables within the funding source sub-samples and found that, consistent with expectations, smaller firms as measured by employees and sales tended to be missing more often from the database.

${ }^{3}$ Approximately $40 \%$ of the SBIR firms subsequently received venture funding. The empirical results are largely robust to: (1) treating these SBIR firms as part of the SBIR pool, (2) treating these firms as part of the VC pool, and (3) dropping them from the analysis. In some instances, the specifications were not robust to industry sector controls.
} 